\title{
Suppression of LPS-Induced Inflammation by Chalcone Flavokawain A through Activation of Nrf2/ARE-Mediated Antioxidant Genes and Inhibition of ROS/NFkB Signaling Pathways in Primary Splenocytes
}

\author{
Hsin-Ling Yang $\left(\mathbb{D},{ }^{1}\right.$ Ting-Yu Yang, ${ }^{1}$ Yugandhar Vudhya Gowrisankar, ${ }^{2}$ Chun-Huei Liao, ${ }^{1}$ \\ Jiunn-Wang Liao, ${ }^{3}$ Pei-Jane Huang $\oplus^{4},{ }^{4}$ and You-Cheng Hseu $\mathbb{C}^{2,4,5,6}$ \\ ${ }^{1}$ Institute of Nutrition, College of Biopharmaceutical and Food Sciences, China Medical University, Taichung 40402, Taiwan \\ ${ }^{2}$ Department of Cosmeceutics, College of Biopharmaceutical and Food Sciences, China Medical University, Taichung 40402, Taiwan \\ ${ }^{3}$ Graduate Institute of Veterinary Pathology, National Chung-Hsing University, Taichung 402, Taiwan \\ ${ }^{4}$ Department of Health and Nutrition Biotechnology, Asia University, Taichung 41354, Taiwan \\ ${ }^{5}$ Chinese Medicine Research Center, China Medical University, Taichung 40402, Taiwan \\ ${ }^{6}$ Research Center of Chinese Herbal Medicine, China Medical University, Taichung 40402, Taiwan
}

Correspondence should be addressed to You-Cheng Hseu; ychseu@mail.cmu.edu.tw

Received 17 March 2020; Revised 2 May 2020; Accepted 18 May 2020; Published 13 June 2020

Academic Editor: Christopher Horst Lillig

Copyright (C) 2020 Hsin-Ling Yang et al. This is an open access article distributed under the Creative Commons Attribution License, which permits unrestricted use, distribution, and reproduction in any medium, provided the original work is properly cited.

Oxidative stress is an important contributing factor for inflammation. Piper methysticum, also known as Kava-kava, is a shrub whose root extract has been consumed as a drink by the pacific islanders for a long time. Flavokawain A (FKA) is a novel chalcone derived from the kava plant that is known to have medicinal properties. This study was aimed at demonstrating the antioxidant molecular mechanisms mediated by FKA on lipopolysaccharide- (LPS-) induced inflammation in BALB/c mousederived primary splenocytes. In vitro data show that the nontoxic concentrations of FKA $(2-30 \mu \mathrm{M})$ significantly suppressed the proinflammatory cytokine (TNF- $\alpha$, IL-1 $\beta$, and IL-6) release but induced the secretion of interleukin-10 (IL-10), an antiinflammatory cytokine. It was also shown that FKA pretreatment significantly downregulated the LPS-induced ROS production and blocked the activation of the NF $\kappa \mathrm{B}$ (p65) pathway leading to the significant suppression of iNOS, COX-2, TNF- $\alpha$, and IL- $1 \beta$ protein expressions. Notably, FKA favored the nuclear translocation of Nrf2 leading to the downstream expression of antioxidant proteins HO-1, NQO-1, and $\gamma$-GCLC via the Nrf2/ARE signaling pathway signifying the FKA's potent antioxidant mechanism in these cells. Supporting the in vitro data, the ex vivo data obtained from primary splenocytes derived from the FKA-preadministered BALB/c mice (orally) show that FKA significantly suppressed the proinflammatory cytokine (TNF- $\alpha$, IL-1 $\beta$, and IL-6) secretion in control-, LPS-, or Concanavalin A- (Con A-) stimulated cells. A significant decrease in the ratios of pro- and anti-inflammatory cytokines (IL-6/IL-10; TNF- $\alpha /$ IL-10) showed that FKA possesses strong anti-inflammatory properties. Furthermore, BALB/c mice induced with experimental pancreatitis using cholecystokinin- (CCK-) 8 showed decreased serum lipase levels due to FKA pretreatment. We conclude that with its potent antioxidant and antiinflammatory properties, chalcone flavokawain A could be a novel therapeutic agent in the treatment of inflammationassociated diseases.

\section{Introduction}

Inflammation is characterized as a protective biological response with complicated mechanisms and implicates immune cells and molecular mediators secreted from the cells that act against pathogens, damaged cells, or other irritants. The inflammation process rules out the initial causes of cell injury, cleans away necrotic cells, and begins tissue 
repairs [1]. There is a dynamic and ever-shifting balance exits between pro- and anti-inflammatory components of the immune system [2]. An uncontrolled shift of this balance towards excessive production of proinflammatory cytokines causes several major cellular events that lead to the pathogenesis and progression of inflammatory responses. Splenocytes are a type of white blood cells from the splenic origin that consists of a variety of $\mathrm{T}$ and $\mathrm{B}$ lymphocytes, dendritic cells, and macrophages which have different immune functions and release various factors in response to inflammatory and anti-inflammatory agents [3]. Various transcription factors and cellular signaling pathways are involved in the expression of proinflammatory genes in macrophages [4].

LPS (the main component of gram-negative bacterial endotoxin) is one of the primary causes of sepsis. The administration of LPS in laboratory animals duplicates that of an experimental inflammatory response. During an inflammation process, the MAPKs p38, JNK, and ERK are involved in the expression of proinflammatory genes. $\mathrm{NF} \kappa \mathrm{B}$ is a crucial factor and plays a major role in the regulation of gene expression patterns of various genes in both innate and adaptive immunities. Upon stimulation with LPS, the activated MAPKs mediate the signaling cascades leading to the activation of $\mathrm{NF} \kappa \mathrm{B}$ in activated macrophages $[4,5]$. Further, LPSmediated splenocyte activation can initiate oxygen uptake to drive oxidative stress-induced inflammation in the immune cells leading to ROS production [6]. Mulder et al. suggested that in response to activation with interferon- $\gamma$ (IFN- $\gamma$ ) and lipopolysaccharide (LPS), spleen-derived macrophages readily acquired a proinflammatory status (M1 type) indicated by the upregulation of nitric oxide (NO) production, prostaglandin E2 (PEG2), tumor necrosis factor- $\alpha$ (TNF- $\alpha$ ), and interleukins through NF $\kappa \mathrm{B}$ activation $[7,8]$. These proinflammatory molecules participate in the development of inflammatory reactions $[9,10]$.

The expression levels of cytoprotective enzymes, which are a response to oxidative stress, are primarily regulated at the transcriptional level. The Nrf2/ARE pathway controls a network of cytoprotective genes that defend against the damaging effects of oxidative and electrophilic stress and inflammation [11]. Nrf2 is an important protein that participates in the coordination of transcriptional induction for various antioxidant enzymes, which also protects them from LPSstimulated inflammation [12]. Nrf2 is a member of the basic leucine zipper (bZIP) family of transcriptional activator proteins, and it is activated by endogenous products of oxidative stress. Nrf2 is bound to Keap-1 and stays in the cytoplasm. Due to the 'inducers,' Nrf2-Keap1 complex disrupts and Nrf2 undergoes rapid translocation to the nucleus, binds to antioxidant response elements (ARE), and induces the expression of antioxidant and phase II enzymes, such as heme oxygenase-1 (HO-1), NAD(P)H-quinone oxidoreductase-1 (NQO-1), gamma-glutamylcysteine synthetase ( $\gamma$-GCLC), glutathione (GSH), and glutathione S-transferase A2 (GSTA2) [13]. This group of enzymes has cytoprotective, antioxidant, and anti-inflammatory effects in endotoxin-induced macrophages. Several new and natural compounds and crude herbal extracts of medicinal herbs induced the expression of phase II detoxifying enzymes in different cell types has been reported. A few of these reports, Nrf2-mediated genes employ antioxidant and anti-inflammatory activities [14]. Therefore, an effective strategy would be to reverse the negative effects of LPS-induced ROS generation through the exogenous supplementation of antioxidants.

Kava-kava, scientifically known as Piper methysticum, is a shrub belonging to the pepper family Piperaceae. It is widely cultivated in various parts of the world, mainly in the Pacific islands. The aqueous root extract of kava has been consumed as a drink that has a strong odor and a pungent taste with sedative, anesthetic, and euphoriant properties. Kavalactones and chalcones are two major phytochemical ingredients present in this plant. The chalcones are derived from flavonoids with a basic molecular structure of two aromatic rings linked by an unsaturated three-carbon bridge. Chalcones in the kava plant can be recognized by their yellow appearance and are named flavokawains. Flavokawain A (FKA) is the major constituent of chalcones $(0.46 \%)$ derived from kava extracts [15]. Splenocytes consist of a variety of cell populations such as T and B lymphocytes, monocytes, and macrophages, which have different immune functions and release different factors in response to the inflammatory and antiinflammatory agents. A previous study indicated that FKA suppresses iNOS and COX-2 expression via blockade of $\mathrm{NF} \kappa \mathrm{B}$ and AP-1 activation in RAW 264.7 macrophages [16]. However, little is known about the anti-inflammatory activity of FKA in splenocytes. In this study, we further demonstrated the molecular signaling pathways associated with FKA-mediated antioxidant and anti-inflammatory properties in primary splenocytes isolated from the BALB/c mice that were challenged to the LPS-induced inflammation.

\section{Materials and Methods}

2.1. Reagents and Antibodies. This study bought Roswell Park Memorial Institute (RPMI)-1640, fetal bovine serum (FBS), Dulbecco's Modified Eagle's medium (DMEM), and penicillin/streptomycin/amphotericin from Gibco BRL/Invitrogen (Carlsbad, CA, USA). We obtained LPS (from Escherichia coli 055: B5), 3-(4,5-dimethylthiazol-2-yl)-2,5-diphenyltetrazolium bromide (MTT), and $2^{\prime}, 7^{\prime}$-dihydrofluorescein-diacetate $\left(\mathrm{DCFH}_{2}-\mathrm{DA}\right)$ from Sigma-Aldrich (St. Louis, MO, USA). We purchased flavokawain A (FKA, purity $\geqq 98 \%$ ) from LKT Laboratories, Inc. (St. Paul, MN, USA). We obtained the antibodies for $\mathrm{p} 65 \mathrm{NF} \kappa \mathrm{B}$, histone H3from Cell Signaling Technology Inc. (Danvers, MA). We purchased antibodies against iNOS, COX-2, Nrf2, NQO- 1 , and $\beta$-actin from Santa Cruz (Heidelberg, Germany). We procured mouse monoclonal antibodies against TNF- $\alpha$, and IL- $1 \beta$ from Abcam (Cambridge, UK). We obtained anti- $\gamma$-GCLC and HO-1 antibodies from Gene Tex Inc. (San Antonio, TX, USA). We obtained all other chemicals and general lab equipment from either Merck \& Co., Inc. (Darmstadt, Germany) or Sigma-Aldrich (St. Louis, MO, USA).

2.2. Laboratory Animals. We purchased 6-8-week-old female BALB/c mice (20-25 g) from the National Animal Center (Taipei, Taiwan). They were maintained in a pathogen-free set up with a 12-h/12-h light/dull cycle. There was free access 
to water and rat chow (Oriental Yeast Co. Ltd., Tokyo, Japan) for all mice [17]. In accordance with "The Guidelines for the Care and Use of Laboratory Animals" suggested by the Chinese Society of Animal Science, Taiwan, all animal experiments in this study were performed as indicated. The animal conventions were endorsed by the Institutional Animal Care and Use Committee (IACUC) of China Medical University.

2.3. Primary Splenocyte Preparation. Primary splenocytes were aseptically isolated from the 8-12-week-old female $\mathrm{BALB} / \mathrm{c}$ mice and kept in the RPMI-1640 medium. This medium was supplemented with $0.1 \%$ of the penicillinstreptomycin-amphotericin solution and $2 \%$ of $50 \mathrm{x}$ tissue culture medium (TCM, a serum substitution purchased from Protide Pharmaceuticals, Inc., Lake Zurich, IL) [18]. Suitable cell numbers were evaluated using the trypan blue exclusion method and a hemocytometer. Segregated splenocytes from every animal were acclimated to a cell density of $1 \times 10^{7}$ cells $/ \mathrm{mL}$ of the RPMI-1640 medium. We procured RAW264.7 (the murine macrophage cell line) from the American Type Culture Collection (ATCC, Rockville, MD, USA). It was then cultured in $1 \%$ penicillin-streptomycin, DMEM containing $2 \mathrm{mM}$ glutamine, and $10 \%$ heat-inactivated $\mathrm{FBS}$ at $37^{\circ} \mathrm{C}$ in a humidified atmosphere with $5 \% \mathrm{CO}_{2}$.

2.4. In Vitro Stimulation Assays. The primary splenocyte or RAW264.7 macrophage cultures were pretreated with FKA for $2 \mathrm{~h}$. After incubation, PBS washed cells were exposed to the fresh medium supplemented with or without LPS (prepared in pH 7.2 PBS). Liu et al. reported that higher concentrations of $(5-20 \mu \mathrm{g} / \mathrm{mL})$ LPS cause significant cytotoxicity to the cells [19]. Also, Kwon et al. demonstrated the inflammation studies in RAW267.4 macrophages by using $1 \mu \mathrm{g} / \mathrm{mL}$ of LPS [16]. Based on this $2.5 \mu \mathrm{g} / \mathrm{mL}$ and $1 \mu \mathrm{g} / \mathrm{mL}$ concentrations of LPS were used for splenocytes and RAW264.7 cells, respectively, in the entire study.

For the measurement of TNF- $\alpha$, IL- $1 \beta$, IL-2, IL-6, or IL10 levels in the cell culture medium, approximately $6.5 \times 10^{5}$ cells/well of splenocytes were cultured in a 12 -well plate. These cells were either treated with FKA $(0-30 \mu \mathrm{M}, 72 \mathrm{~h})$ to measure the effect of FKA on cytokine secretion (or) pretreated with FKA $(0-30 \mu \mathrm{M}, 2 \mathrm{~h})$ followed by LPS $(2.5 \mu \mathrm{g} / \mathrm{mL}$, $72 \mathrm{~h}$ ) to measure the protective effect of FKA on cytokine secretion from LPS-stimulated cells using the ELISA method. The cytokines, TNF- $\alpha$, IL- $1 \beta$, IL-2, IL- 6 , or IL- 10 were quantified by their respective ELISA kits (R\&D Systems, Minneapolis, MN, USA) using the manufacturer's protocols [20].

2.5. MTT Assay. MTT colorimetric assay measured the effect of FKA on cell viability [21]. Splenocytes $\left(1 \times 10^{7}\right.$ cells $/ \mathrm{mL}$ in 96-well plate) or macrophages $\left(4 \times 10^{5}\right.$ cells $/ \mathrm{mL}$ in 12 -well plate) were pretreated with FKA for $2 \mathrm{~h}$, followed by treatment with or without LPS $(2.5$ or $1 \mu \mathrm{g} / \mathrm{mL})$ for $72 \mathrm{~h}$. After treatment, MTT $(0.5 \mathrm{mg} / \mathrm{mL})$ was added to each well and incubated at $37^{\circ} \mathrm{C}$ for $4 \mathrm{~h}$. After the incubation period, using the $400 \mu \mathrm{L}$ DMSO, MTT formazan crystals were dissolved and the absorbance $\left(\mathrm{A}_{570}\right)$ was measured through an ELISA microplate reader ( $\mu$-Quant, Winooski, VT, USA). The cell viability was expressed as a percentage using the following formula: (treated cells/untreated cells) $\times 100$.

2.6. Measurement of Intracellular ROS Accumulation. The intracellular ROS accumulation was measured by the $\mathrm{DCFH}_{2}$-DA fluorescence dye method [22]. Briefly, $1 \times 10^{7}$ cells $/ \mathrm{mL}$ were seeded in a 6 -well plate (primary splenocytes) or $4 \times 10^{5}$ cells $/ \mathrm{mL}$ were seeded in a 12 -well plate (RAW 264.7 macrophages) and then pretreated with different concentrations of FKA (for $2 \mathrm{~h}$ ) followed by treatment with or without LPS. After incubation, $10 \mu \mathrm{M}$ of $\mathrm{DCFH}_{2}-\mathrm{DA}$ was added to the culture medium and the incubation was continued for $30 \mathrm{~min}$ at $37^{\circ} \mathrm{C}$. The intracellular ROS, as indicated by the dichlorofluorescein (DCF) fluorescence intensity, was measured using a Becton-Dickinson FACSCalibur flow cytometer for suspended primary splenocytes (Becton Dickinson, NJ) or fluorescence microscopy for adherent RAW 264.7 macrophages (200x magnification, Olympus, Center Valley, PA, USA). The ROS levels were measured by comparing the exhibited fluorescence intensity from any treated cells compared to the vehicle-treated cells and were assigned to 1fold arbitrarily.

2.7. Preparation of Cell Extracts and Western Blot Analysis. Approximately $1 \times 10^{7}$ cells $/ \mathrm{mL}$ of primary splenocytes (seeded in $60 \mathrm{~mm}$ dish) or $4 \times 10^{6}$ cells $/ \mathrm{mL}$ of RAW264.7 macrophages (seeded in a $100 \mathrm{~mm}$ dish) pretreated with different concentrations of FKA $(2.5-30 \mu \mathrm{M})$ for $2 \mathrm{~h}$ followed by exposing to LPS $(2.5$ or $1 \mu \mathrm{g} / \mathrm{mL})$ at different time points $(1-$ $24 \mathrm{~h})$. The untreated cells were the control cells. After treatment, the cytoplasmic, nuclear fractions of the proteins were harvested using protein extracting reagents (Pierce Biotechnology, Rockford, IL, USA). The concentrations of extracted protein fractions were measured using the BCA protein assay method (Bio-Rad, Hercules, CA, USA). Equal quantities of denatured proteins $(50 \mu \mathrm{g})$ were resolved on $8-15 \%$ gradient SDS-PAGE, followed by transfer on to PVDF membranes. Blocking buffer was used to block these (5\% nonfat dry milk for $30 \mathrm{~min}$ ) and then incubation with various primary antibodies overnight. On the next day, membranes were washed and incubated with secondary antibodies for $2 \mathrm{~h}$. After the incubation, PBS-washed membranes were developed and the protein bands were visualized using a chemiluminescence substrate (Pierce Biotechnology, Rockford, IL, USA). Using AlphaEase (Genetic Technology Inc. Miami, FL, USA) densitometric analysis was carried out and the protein expression data were represented as fold over control. Throughout the western blot experiments, either $\beta$-actin (for cytosolic proteins) or histone (for nuclear proteins) proteins were considered internal protein controls [23].

2.8. In Vivo Demonstration of Pro- and Anti-inflammatory Cytokine Levels in Control-, LPS-, or Con A-Stimulated Splenocytes Isolated from the FKA-Administered BALB/c Mice. Eight $\mathrm{BALB} / \mathrm{c}$ mice were randomly segregated into two groups of four mice each. These mice were orally administered with 0 (control) or $30 \mathrm{mg} / \mathrm{kg}$ of FKA (solubilized in $0.1 \% \mathrm{DMSO}$ ) for $4 \mathrm{~h}$. At the end of the incubation period, all mice were sacrificed and primary splenocytes were 
aseptically isolated as per the procedure described above [18]. Primary splenocytes were seeded in 12 -well plates $\left(1 \times 10^{7}\right.$ cells $/ \mathrm{mL}$ ) and were stimulated with control (saline), LPS $(2.5 \mu \mathrm{g} / \mathrm{mL})$, or concanavalin A (Con A, $2.5 \mu \mathrm{g} / \mathrm{mL})$ for $72 \mathrm{~h}$. After the incubation period, the concentrations of secreted TNF- $\alpha$, IL-1 $\beta$, IL-2, IL-6, or IL-10 levels in the control-, LPS-, or Con A- stimulated cell culture medium were measured using the ELISA kits (R\&D Systems, Minneapolis, $\mathrm{MN}, \mathrm{USA}$ ) in accordance with the manufacturer's protocol.

2.9. Determination of Serum Lipase Concentrations in Cholecystokinin-8- (CCK-8-) Induced Experimental Pancreatitis of $B A L B / c$ Mice. Twenty BALB/c mice were randomly placed into five different groups and each group was made up of four mice. The mice were administered either oral administration of FKA (in $0.1 \%$ DMSO) and/or intraperitoneal (IP) injections of cholecystokinin-8 (CCK-8). The treatments were as follows: (a) vehicle (0.1\% DMSO), (b) $100 \mu \mathrm{g} / \mathrm{kg}$ of CCK-8 alone, (c) $15 \mathrm{mg} / \mathrm{kg}$ of $\mathrm{FKA}+100 \mu \mathrm{g} / \mathrm{kg}$ of CCK-8, (d) $30 \mathrm{mg} / \mathrm{kg}$ of FKA $+100 \mu \mathrm{g} / \mathrm{kg}$ of CCK- 8 , and (e) $30 \mathrm{mg} / \mathrm{kg}$ of FKA alone. In the case of groups ' $c$ ' and 'd,' CCK-8 was injected into the mice for $0.5,1.5,2.5$, and $4 \mathrm{~h}$ after the oral administration of FKA [22]. After the CCK-8 injections, the blood samples for the mice were collected from the retroorbital sinus and the serum lipase levels were measured by using a commercial serum lipase ELISA kit (R\&D System, Minneapolis, MN, USA).

2.10. Statistical Analyses. In this study, data were represented as mean \pm standard deviation (mean $\pm \mathrm{SD}$ ) of three or more independent experiments. All data were analyzed using analysis of variance (ANOVA), followed by Dunnett's test for pairwise comparison. Statistical significance was assigned as ${ }^{*} p<0.05,{ }^{* *} p<0.01$, and ${ }^{* * *} p<0.001$ compared to the untreated control cells and ${ }^{\#} p<0.05,{ }^{\# \#} p<0.01$, and $\# \#<0.001$ compared to the LPS-treated group.

\section{Results}

3.1. FKA Mediated Differential Secretion Patterns of Pro- and Anti-inflammatory Cytokines in Primary Splenocytes. We first determined the subtoxic dosage of FKA (Figure 1(a)) on primary splenocytes derived from the $\mathrm{BALB} / \mathrm{c}$ mice. Primary splenocytes were treated with increasing concentrations of FKA (1 to $60 \mu \mathrm{M}$ ) or $2.5 \mu \mathrm{g} / \mathrm{mL}$ of LPS for $72 \mathrm{~h}$. After incubation has concluded, an MTT assay was conducted to determine cell viability. The data showed that compared with control cells, splenocytes exposed to FKA did not enhance the proliferative state of splenocytes and did not induce any significant toxicity as well [24]. Based on these observations, $30 \mu \mathrm{M}$ FKA has been used as the maximum concentration in the entire study (Figure 1(b)). Later, we tested the effect of FKA concentration on the secretion patterns of pro- and anti-inflammatory cytokines in the FKAstimulated primary splenocyte cell culture medium. ELISA data showed that FKA dose dependently and significantly suppressed the release of proinflammatory TNF- $\alpha$, IL- $1 \beta$, and IL-2 but upregulated the release of anti-inflammatory IL-10 from primary splenocytes (Figures $1(\mathrm{c})-1(\mathrm{f})$ ). This data suggested that FKA showed anti-inflammatory properties in primary splenocytes.

3.2. FKA Suppressed the LPS-Induced Proinflammatory Cytokine Secretion in Primary Splenocytes. The antiinflammatory efficacy of FKA was demonstrated in LPSstimulated primary splenocytes. Cells were pretreated with different concentrations $(0,2-30 \mu \mathrm{M})$ of FKA for $2 \mathrm{~h}$ followed by LPS stimulation $(2.5 \mu \mathrm{g} / \mathrm{mL})$ for $72 \mathrm{~h}$. Figure 2 shows that, in comparison with control cells, LPS alone stimulation has significantly enhanced the productions of both TNF- $\alpha$, IL- $1 \beta$, IL-2, and IL- 6 and IL-10 cytokines. However, FKA pretreatment dose dependently and significantly suppressed the release of proinflammatory cytokines (TNF- $\alpha$, IL- $1 \beta$, IL-2, and IL-6) signifying the protective role of FKA in LPS-induced inflammation in primary splenocytes. Interestingly, FKA has a negligible effect on LPS-stimulated antiinflammatory IL-10 secretion.

3.3. FKA Dose Dependently Suppressed the Intracellular ROSMediated NFKB Activation and Its Associated Inflammatory Cytokines in LPS-Stimulated Primary Splenocytes. ROS plays an important role in the modulation of various inflammatory mediators [25]. The generation of intracellular ROS was measured using the $\mathrm{DCFH}_{2}$-DA fluorescence method. Splenocytes were pretreated with different concentrations of FKA $(0,2-30 \mu \mathrm{M}$ for $2 \mathrm{~h})$ followed by LPS stimulation $(2.5 \mu \mathrm{g} / \mathrm{mL})$ for $18 \mathrm{~h}$. These cells were used to measure the accumulation of intracellular ROS levels. Flow cytometry data indicated that FKA pretreatment dose dependently and significantly attenuated the LPS-induced ROS accumulation (Figure 3(a)).

Multiple aspects of innate and adaptive immune functions are regulated by the transcription factor $\mathrm{NF} \kappa \mathrm{B}$. It also serves as an important mediator of an inflammatory response [7]. We also tested the role of $\mathrm{NF} \kappa \mathrm{B}$ in the suppression of inflammation in FKA-pretreated and LPS-stimulated splenocytes. Western blot data obtained from the splenocyte nuclear protein extracts showed that LPS $(2.5 \mu \mathrm{g} / \mathrm{mL}$ for $1 \mathrm{~h})$ stimulation induced a remarkable increase in the p65 levels. Similar to the ROS data, FKA pretreatment significantly attenuated the LPS-induced p65 levels at all the concentrations of FKA (Figure 3(b)).

Later, we tested the effect of FKA pretreatment on the expression patterns of iNOS and COX-2 enzymes and TNF- $\alpha$ and IL- $1 \beta$ (proinflammatory cytokines). Western blot data showed that $2.5 \mu \mathrm{g} / \mathrm{mL}$ LPS stimulation (for $18 \mathrm{~h}$ ) overexpressed the expressions of iNOS, COX-2, TNF- $\alpha$, and IL-1 $\beta$. However, this effect was significantly and remarkably suppressed in the present higher concentrations of FKA $(>7.5 \mu \mathrm{M})$ suggesting that FKA suppressed the transcriptional activation of p65 leading to further suppression of inflammatory enzymes and cytokine expressions (Figures 3(c)-3(f)).

3.4. FKA Mediated Antioxidant Gene Expression via Nrf2 Pathway in Primary Splenocytes. Previous studies have shown that Nrf2 is a part of the anti-inflammatory process because it mediates the recruitment of inflammatory cells 


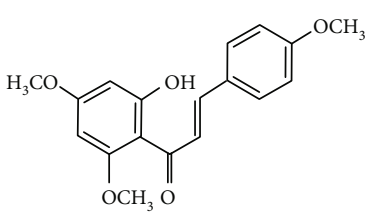

Flavokawain A (FKA)

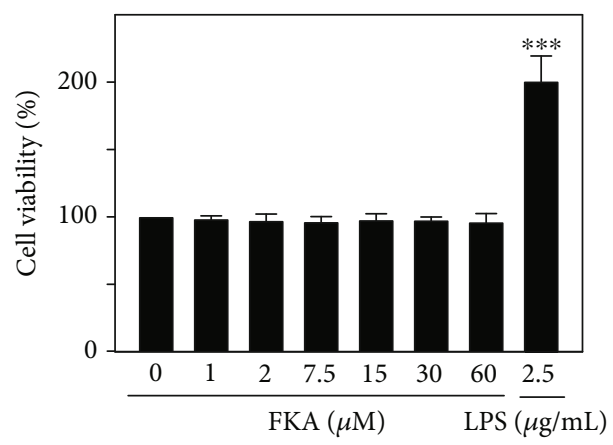

(b)

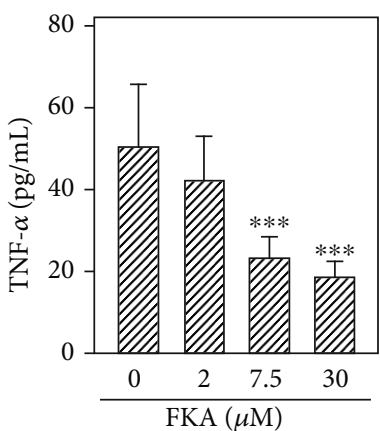

(c)

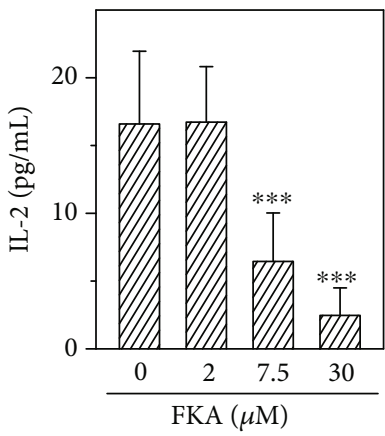

(e)

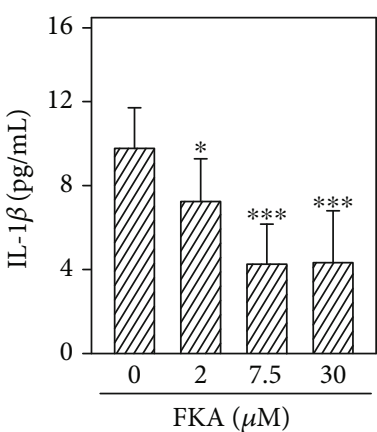

(d)

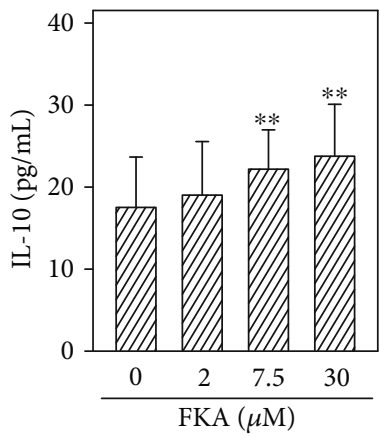

(f)

FIGURE 1: FKA attenuated the secretions of proinflammatory TNF- $\alpha$, IL-1 $\beta$, and IL-2 levels but enhanced the anti-inflammatory IL-10 levels in primary splenocyte cell culture medium. (a) Chemical structure of flavokawain A (FKA). (b) Effect of FKA on cell viability. Cells were treated with FKA $(1-60 \mu \mathrm{M})$ or LPS $(2.5 \mu \mathrm{g} / \mathrm{mL})$ for $72 \mathrm{~h}$. Cell viability was determined by MTT assay. (c-f) Splenocytes were pretreated with $0,2,7.5$, and $30 \mu \mathrm{M}$ of FKA for $72 \mathrm{~h}$. After the incubation period, the levels of pro- and anti-inflammatory cytokines in the cell culture medium were measured by commercial ELISA kits. The data were represented as the mean \pm SD of six experiments. Statistical significance was assigned as ${ }^{*} p<0.05,{ }^{* *} p<0.01$, and ${ }^{* * *} p<0.001$ compared to the control cells.

and regulates gene expression via the antioxidant response element (ARE). Anti-inflammatory gene expression is primarily regulated by the Keap-1/Nrf2/ARE signaling pathway. It also inhibits the progression of inflammation [26]. To test this, primary splenocytes were treated with $30 \mu \mathrm{M}$ FKA for $1-4 \mathrm{~h}$ and the expression of nuclear translocation of Nrf2 protein was measured via the western blot method. Data showed that FKA time dependently induced the nuclear translocation of $\mathrm{Nrf} 2$ with a significant increase in the expression of $\mathrm{Nrf} 2$ at $3 \mathrm{~h}$ time point (Figure 4(a)). The data shows that FKA is crucial in the activation and nuclear translocation of Nrf2 in splenocytes. Further, we demonstrated the effect of time on the FKAmediated downstream expressions of HO-1, NQO-1, and
$\gamma$-GCLC antioxidant proteins. Primary splenocytes were treated with $30 \mu \mathrm{M}$ FKA for $1-24 \mathrm{~h}$, and the protein expression of various antioxidant proteins was measured. The western blot data in this study showed that FKA treatment time dependently upregulated the expressions of the HO-1, NQO-1, and $\gamma$-GCLC proteins with the maximum expressions observed at longer time points $(>6 \mathrm{~h}$ ) (Figure 4(b)). The data were calculated as the fold-over basal levels of antioxidant protein expression at different time points that were normalized with the $\beta$-actin internal control and represented as the ratio value. Data showed that FKA has a differential but significant effect on the expression patterns of HO-1, NQO-1, and $\gamma$-GCLC antioxidant proteins (Figures $4(\mathrm{c})-4(\mathrm{e})$ ). 


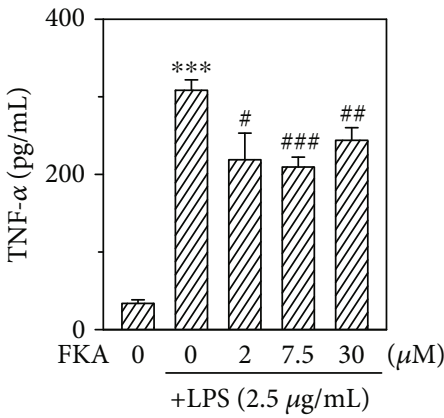

(a)

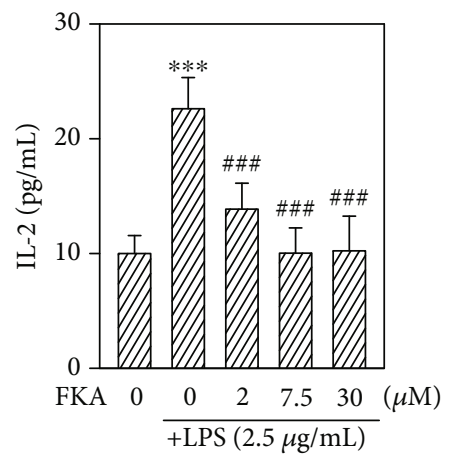

(c)

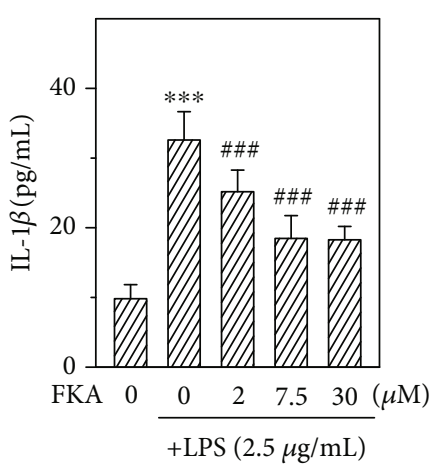

(b)

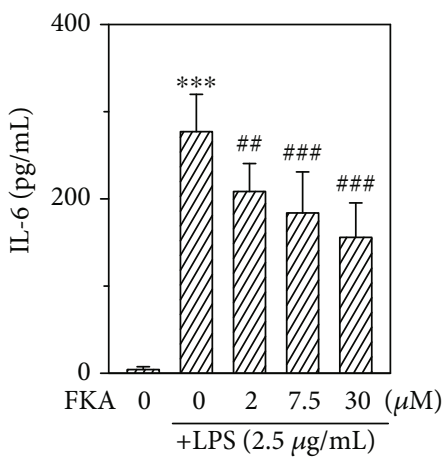

(d)

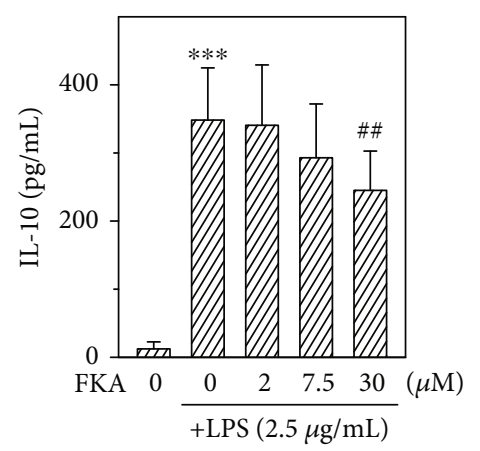

(e)

Figure 2: FKA suppressed the LPS-induced TNF- $\alpha$, IL-1 $\beta$, IL-2, and IL-6 secretions in primary splenocytes. Splenocytes were pretreated with FKA $(0,2-30 \mu \mathrm{M})$ for $2 \mathrm{~h}$, followed by LPS $(2.5 \mu \mathrm{g} / \mathrm{mL})$ stimulation for $72 \mathrm{~h}$. The secretions of TNF- $\alpha$ (a), IL-1 $\beta$ (b), IL-2 (c), IL-6 (d), and IL10 (e) were measured through commercial ELISA kits. The data were represented as the mean \pm SD of three experiments. Statistical significance was assigned as ${ }^{* * *} p<0.001$ compared to the control cells and ${ }^{\#} p<0.05,{ }^{\# \#} p<0.01$, and ${ }^{\# \# \#} p<0.001$ compared to the LPStreated cells.

3.5. FKA Induced ROS Production in Primary Splenocytes. Nrf2 activation regulates several signaling cascades, including ROS. They are formed as a natural byproduct of the normal metabolism of oxygen and have important roles in cell signaling and homeostasis. Although ROS are harmful, low concentrations of ROS are believed to be involved in redox signaling that may contribute to normal cellular functions, adaptation, and disease prevention [27]. In this study, we tested the effect of FKA-mediated ROS generation in primary splenocytes. For this, cells were treated with FKA $(30 \mu \mathrm{M})$ for 0-60 min and the generation of intracellular ROS levels were measured by the DCF fluorescence method. Our flow cytometry data indicated that compared to the untreated control cells, FKA significantly upregulated (approximately 1.5 -fold) the induction of ROS within 5 min after exposure to FKA in primary splenocytes and this pattern was continued up to $60 \mathrm{~min}$ (Figures 5(a) and 5(b)).

3.6. Effect of Pro- and Anti-inflammatory Cytokine Expression in LPS- or Con A-Stimulated Primary Splenocytes Isolated from the In Vivo FKA Pretreatment to the BALB/c Mice. Primary splenocytes were isolated from the BALB/c mice that were administered with FKA. These cells were stimulated with saline (control), LPS $(2.5 \mu \mathrm{g} / \mathrm{mL})$, or Con A $(2.5 \mu \mathrm{g} / \mathrm{mL})$ for $72 \mathrm{~h}$, and the effect of in vivo FKA pretreatment on the expression patterns of TNF- $\alpha$, IL- $1 \beta$, IL-2, and IL- 6 and IL10 were measured by the secretion of related cytokines in a cell culture medium using an ELISA kit for each cytokine. 


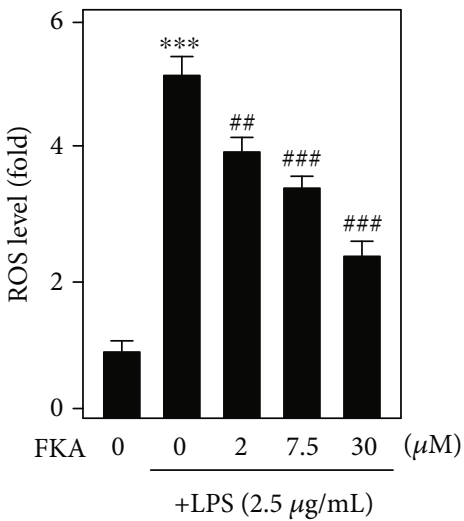

(a)

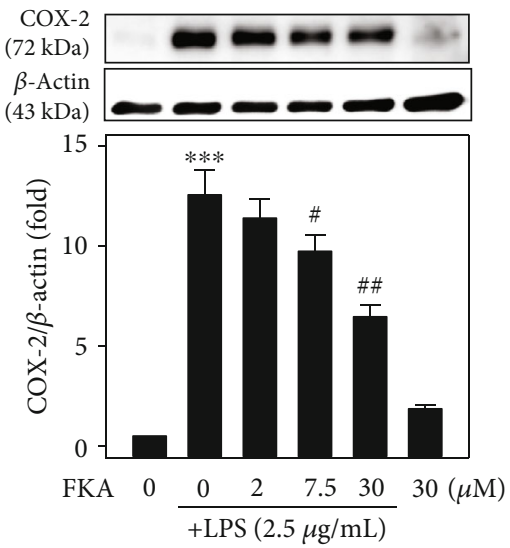

(d)

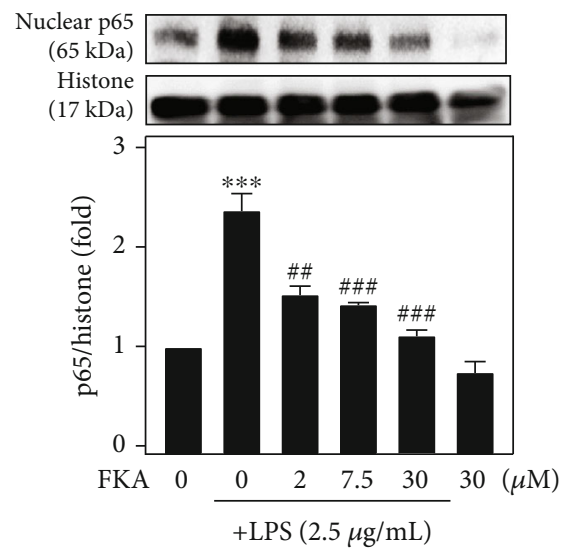

(b)

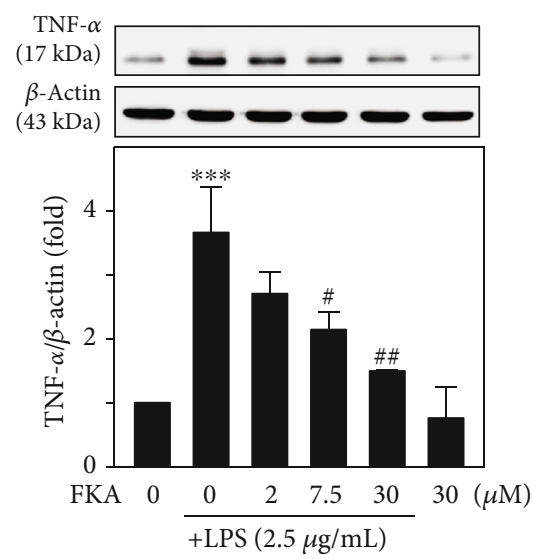

(e)

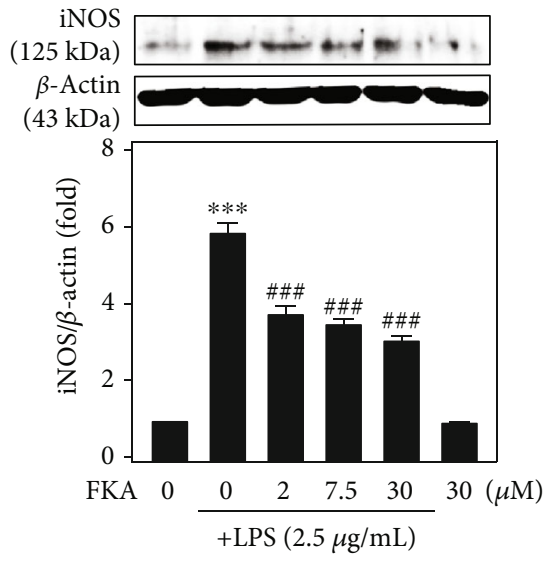

(c)

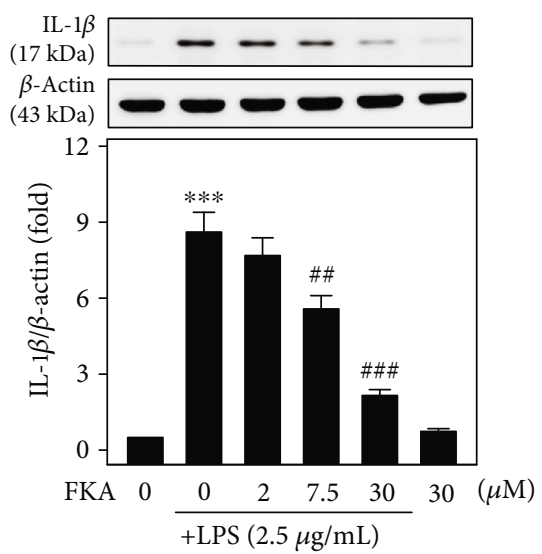

(f)

FIgURE 3: LPS-stimulated ROS levels, NF $\kappa$ B activation, and iNOS, COX-2, TNF- $\alpha$, and IL- $1 \beta$ protein expressions were suppressed in FKApretreated primary splenocytes. (a) Primary splenocytes were pretreated with FKA (0, 2-30 $\mu \mathrm{M}$ for $2 \mathrm{~h}$ ) followed by stimulation with LPS $(2.5 \mu \mathrm{g} / \mathrm{mL})$ for $18 \mathrm{~h}$. The intracellular ROS levels were measured by the DCF fluorescence technique using the flow cytometry method. (b) Western blotting showing the changes in NF $\kappa$ B (p65). Cells were pretreated with FKA (2.5-30 $\mu \mathrm{M})$ for $2 \mathrm{~h}$, followed by LPS stimulation $(2.5 \mu \mathrm{g} / \mathrm{mL})$ for $1 \mathrm{~h}$. (c-f) Western blotting showing the changes in iNOS (c), COX-2 (d), TNF- $\alpha$ (e), and IL-1 $\beta$ (f) levels. Cells were pretreated with FKA $(0,2-30 \mu \mathrm{M}, 2 \mathrm{~h})$ followed by LPS stimulation $(2.5 \mu \mathrm{g} / \mathrm{mL}, 18 \mathrm{~h})$. Equal concentrations of protein samples $(50 \mu \mathrm{g})$ were resolved on $8-15 \%$ SDS-PAGE. The results obtained were mean \pm SD of three experiments. Statistical significance was assigned as ${ }^{*} p<0.05,{ }^{* *} p<0.01$, and ${ }^{* * *} p<0.001$ compared to the control cells and ${ }^{\#} p<0.05,{ }^{\# \#} p<0.01$, and ${ }^{\# \# \#} p<0.001$ compared to the LPStreated cells.

Our data showed that FKA pretreatment significantly downregulated the production of TNF- $\alpha$, IL- $1 \beta$, IL- 2 , and IL- 6 in the control-, LPS-, or Con A-stimulated splenocytes. In contrast to this, IL-10 levels were upregulated in the control- or Con A-stimulated splenocytes. But, this upregulation was not statistically significant. Interestingly, the TNF- $\alpha / \mathrm{IL}-10$ and IL-6/IL-10 ratio values were decreased in the FKAtreated group which was statistically significant. All this data suggested that FKA pretreatment plays an anti-inflammatory role in primary splenocytes (Table 1 ).

3.7. FKA Attenuated Serum Lipase Levels in BALB/c Mice Induced with Experimental Pancreatitis. Seifert et al. have suggested that serum lipase levels are an important marker characterized by an upregulation that can be observed in animals who were given pancreatitis [28]. In this study, BALB/c mice were orally administered with FKA (15 or $30 \mathrm{mg} / \mathrm{kg}$ in $0.1 \% \mathrm{DMSO}$ ) for $2 \mathrm{~h}$, which was then followed by intraperito- neal (i.p.) injections of cholecystokinin-8 (CCK-8) for 0.5 , $1.5,2.5$, and $4 \mathrm{~h}$. After treatment, blood samples were collected from all mice and the serum lipase levels were estimated using the ELISA kits. Our results showed that mice injected with CCK-8 alone showed significantly elevated serum lipase levels. This effect was significantly attenuated by FKA. The data clearly showed the anti-inflammatory properties of FKA (Figure 6).

\subsection{FKA Attenuates LPS-Stimulated ROS Generation through} the Nrf2/ARE Signaling Pathways in Murine RAW 264.7 Macrophages. FKA suppressed the expression of iNOS and COX-2 and then the production of NO and PGE2 in the LPS-stimulated murine RAW264.7 macrophages [16]. Further, FKA inhibited the activation of the NF $\kappa$ B and AP-1 signaling pathways [16]. Therefore, RAW 264.7 cells were used to investigate the FKA-activated Nrf2/ARE signaling pathways as involved in the suppression of LPS-induced 


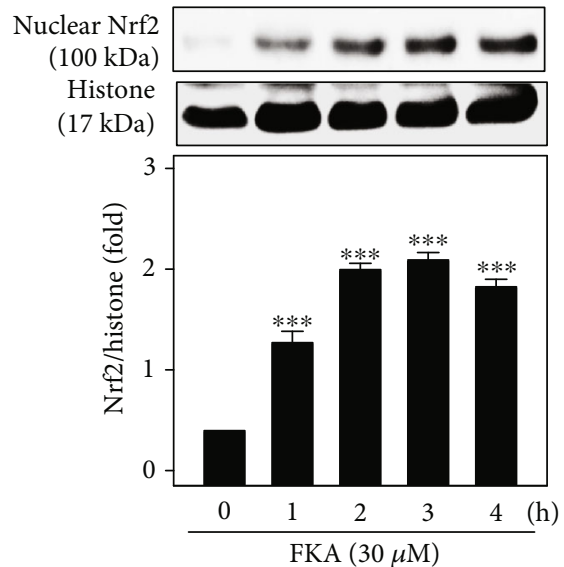

(a)

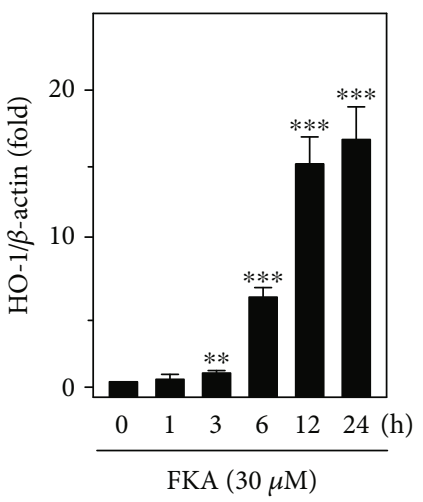

(c)

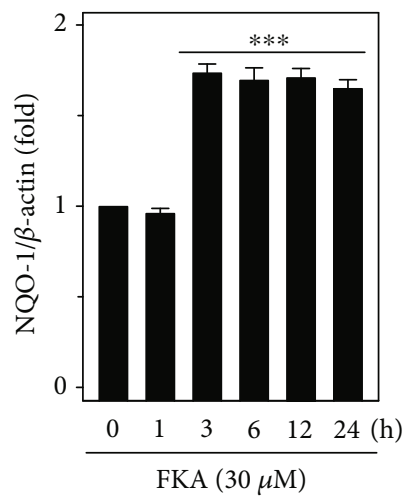

(d)

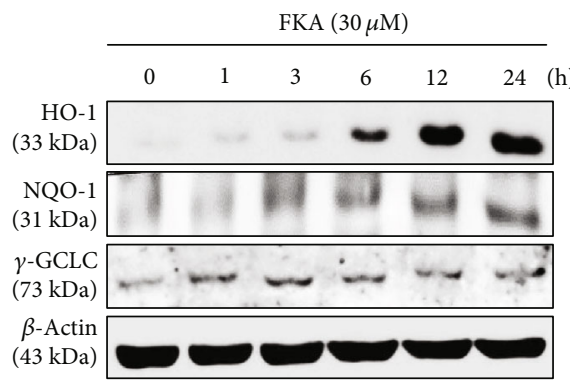

(b)

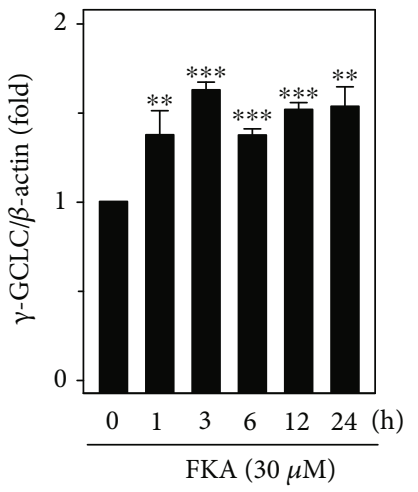

(e)

FIGURE 4: FKA induced HO-1, NQO-1, and $\gamma$-GCLC antioxidant gene expression via the Nrf2 signaling pathway in primary splenocytes. (a) Nuclear translocation of Nrf2 was mediated by FKA. Cells were treated with $30 \mu \mathrm{M}$ FKA for $1-4 \mathrm{~h}$. Using the western blot technique, the expression of nuclear Nrf2 levels was measured against the internal control protein histone. (b-e) FKA mediated the upregulation of HO1 , NQO-1, and $\gamma$-GCLC proteins. Cells were treated with $30 \mu \mathrm{M}$ FKA for $1-24 \mathrm{~h}$. The expressions of HO-1, NQO-1, and $\gamma$-GCLC proteins were determined by western blot method and were represented as fold change over the untreated control splenocytes. $\beta$-Actin acts as an internal protein control. Results were calculated as fold change over the control splenocytes that were arbitrarily assigned the value of $100 \%$. Data were represented as mean \pm SD of three experiments. Statistical significance was assigned as ${ }^{* *} p<0.01 ;{ }^{* * *} p<0.001$ compared to the control cells.

inflammation. We first tested the effect of FKA on the viability of RAW 264.7 cells. These macrophages were exposed to increasing concentrations of FKA $(0,1-60 \mu \mathrm{M})$ for $2 \mathrm{~h}$ and then stimulated without or with LPS $(1 \mu \mathrm{g} / \mathrm{mL})$ for $24 \mathrm{~h}$. After treatments, an MTT assay was performed to measure its viability. Data showed that up to $30 \mu \mathrm{M}$ concentrations, FKA was nontoxic to macrophages (i.e., no significant reductions in macrophage cell viability). However, at $60 \mu \mathrm{M}$ concentrations, FKA was able to suppress macrophage cell viability by $\sim 20 \%$ (Figure $7(\mathrm{a})$ ).

Later, the effect of time on the FKA-mediated antioxidant protein expression in RAW 264.7 cells was determined. Cells were treated with $30 \mu \mathrm{M}$ of FKA for 1-24h. Subsequently, the expression pattern of Nrf2, HO-1, and NQO-1 proteins was measured by the western blot method. As shown in Figure 7(b), FKA has a differential effect on the expression patterns of these proteins at various time points. The expression of Nrf2 and HO- 1 proteins were initiated $1 \mathrm{~h}$ after the FKA treatment that lasted up to $12 \mathrm{~h}$. However, the substan- tial expression of the NQO- 1 protein occurred from an $8 \mathrm{~h}$ time point and increased towards the longer time points (Figure 7(b)). Hence, FKA has a significant effect on the antioxidant protein expression in murine macrophage cells (Figure 7(b)). We further tested the effect of FKA concentration on the LPS-stimulated ROS generation in RAW 264.7 cells. Macrophages were pretreated with different concentrations of FKA $(0,2.5-10 \mu \mathrm{M})$ for $2 \mathrm{~h}$ followed by stimulated with or without LPS $(1 \mu \mathrm{g} / \mathrm{mL})$ for $24 \mathrm{~h}$. The generation of intracellular ROS levels was measured through the DCF fluorescence method using fluorescence microscopy. Our data showed that in LPS alone-stimulated cells, ROS levels were dramatically increased (Figures 7 (c) and 7(d)). However, this effect was suppressed with increasing concentrations of FKA with a significant suppression observed at $10 \mu \mathrm{M}$ FKA concentration (Figures $7(\mathrm{c})$ and $7(\mathrm{~d})$ ). These results provided direct evidence that FKA plays a key anti-inflammatory and antioxidant role through the induction of Nrf2, HO-1, and NQO-1 antioxidant gene expression in LPS-stimulated macrophages. 

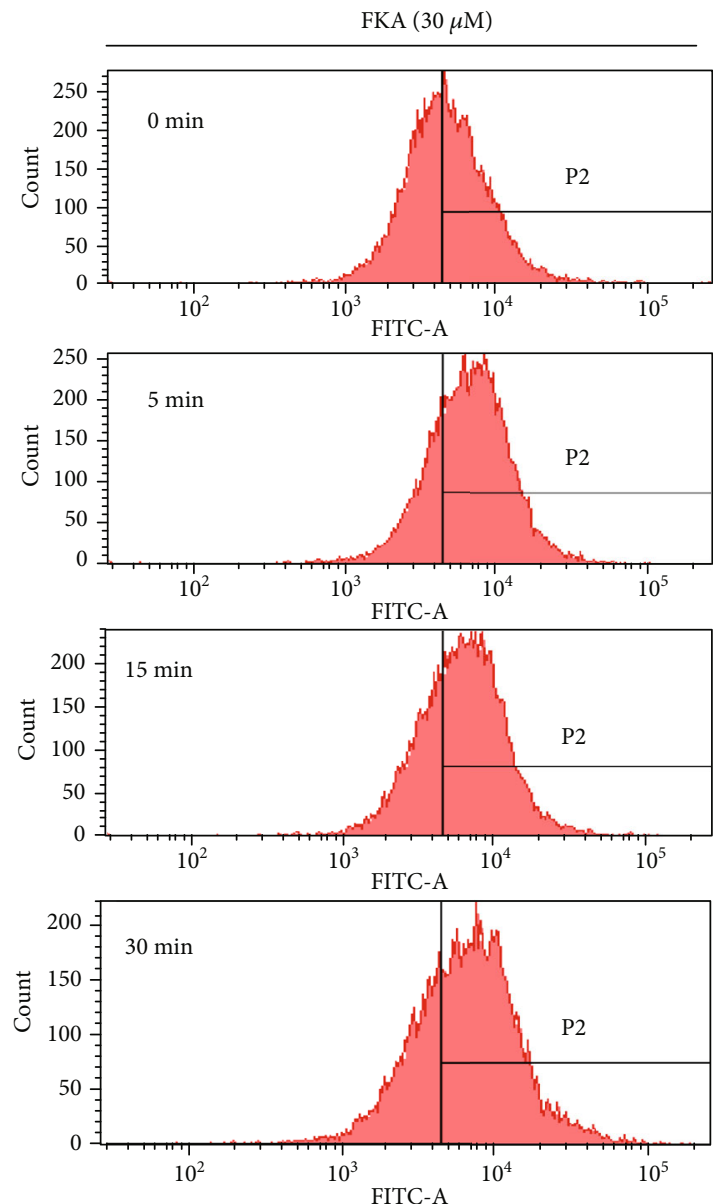

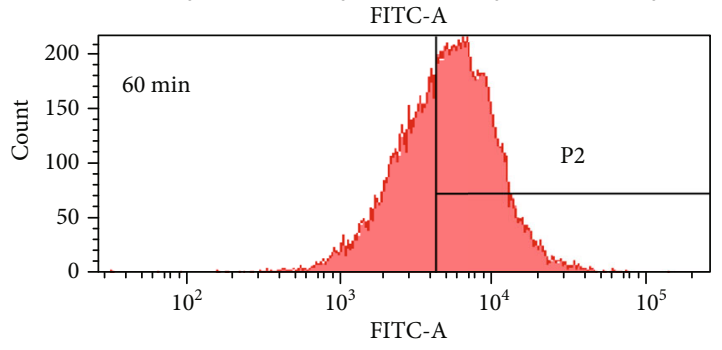

(a)

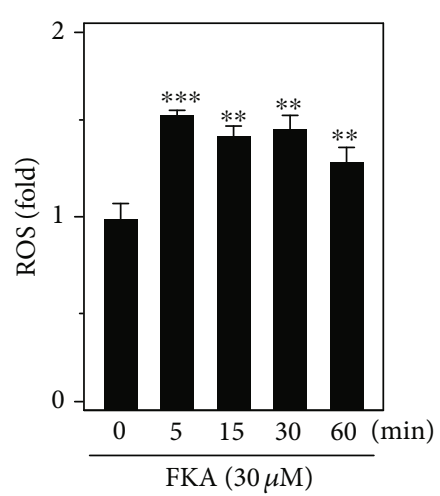

(b)

FIGURE 5: FKA induced ROS generation in primary splenocytes. (a) Splenocytes were pretreated with FKA (30 $\mu \mathrm{M})$ for $0-60$ min. The generation of intracellular ROS levels was indicated by the DCF fluorescence method that was measured by flow cytometry. (b) Data were presented as fold change of ROS over the FKA untreated control cells. Results were represented as the mean \pm SD of three experiments. Statistical significance was assigned as ${ }^{*} p<0.05,{ }^{* *} p<0.01$, and ${ }^{* * *} p<0.001$ compared to the control cells.

\section{Discussion}

Inflammatory responses are a defense mechanism against infection and injury. But, sustained inflammation is a condition caused by the overexpression of several proinflammatory cytokines or their associated derivatives [29]. For example, iNOS and COX-2 are often responsible for chronic inflammation leading to various inflammation-associated diseases including different types of cancers [30]. The proinflammatory transcription factor $\mathrm{NF} \kappa \mathrm{B}$ is one of the key factors that regulate these cytokine productions. Therefore, modulating proinflammatory mediators in the macrophages is a good strategy for the treatment of various inflammatory diseases. In this connection, flavonoids, with the characteristic feature of inhibiting the induction of inflammatory cytokines are considered to be an interesting tool for the control of inflammation [31]. In this study, using primary splenocytes isolated from the $\mathrm{BALB} / \mathrm{c}$ mice as the cellular model system, we demonstrated the anti-inflammatory efficacy of FKA. MTT data showed that FKA (Figure 1(a)) treatment has a negligible effect on the splenocyte cell viability. However, $2.5 \mu \mathrm{g} / \mathrm{mL}$ of LPS (used as a positive control) has significantly increased the proliferation of primary splenocytes (Figure 1(b)). Similar observation was also reported in one of the previous reports in which LPS has significantly promoted the proliferation of splenocytes from WT mice. Their 
TABLE 1: Pro- and anti-inflammatory cytokine secretion patterns in saline-, LPS-, or Con A-stimulated primary splenocytes derived from FKA pretreated BALB/c mice. LPS- or Con A-stimulated TNF- $\alpha$, IL-1 $\beta$, IL-2, and IL-6 secretions were suppressed in primary splenocytes derived from the FKA-pretreated BALB/c mice. BALB/c mice were administered with $30 \mathrm{mg} / \mathrm{kg}$ of FKA for $4 \mathrm{~h}$. After the treatment, primary splenocytes were isolated and maintained. These cells were stimulated with saline, LPS $(2.5 \mu \mathrm{g} / \mathrm{kg})$, or Con A $(2.5 \mu \mathrm{g} / \mathrm{kg})$ for $72 \mathrm{~h}$, and the secretions of proinflammatory TNF- $\alpha$, IL- $1 \beta$, IL- 2 , and IL- 6 cytokines as well as anti-inflammatory IL-10 cytokine were measured using the commercial ELISA kits. Results were represented as the mean \pm SD of three experiments. Statistical significance was assigned as ${ }^{*} p<$ $0.05 ;{ }^{* *} p<0.01$; and ${ }^{* * *} p<0.001$ compared to the values obtained from primary splenocytes that were derived from the mice not administered with FKA.

\begin{tabular}{|c|c|c|c|}
\hline Cytokine $(\mathrm{pg} / \mathrm{mL})$ & Treatment & Control $(n=4)$ & $\begin{array}{c}\text { FKA }(30 \mathrm{mg} / \mathrm{kg}) \\
(n=4)\end{array}$ \\
\hline \multirow{3}{*}{ TNF- $\alpha$} & Saline & $110.0 \pm 21.6$ & $33.5 \pm 6.5^{*}$ \\
\hline & LPS & $250.7 \pm 23.3$ & $40.0 \pm 7.3^{* * *}$ \\
\hline & Con A & $194.4 \pm 30.8$ & $84.5 \pm 19.6^{*}$ \\
\hline \multirow{3}{*}{ IL- $1 \beta$} & Saline & $25.9 \pm 0.6$ & $18.5 \pm 1.3^{* *}$ \\
\hline & LPS & $46.2 \pm 5.0$ & $25.4 \pm 0.9^{* *}$ \\
\hline & Con A & $21.3 \pm 1.6$ & $18.0 \pm 0.9$ \\
\hline \multirow{3}{*}{ IL-2 } & Saline & $16.2 \pm 2.3$ & $7.1 \pm 2.0^{*}$ \\
\hline & LPS & $19.2 \pm 4.2$ & $9.2 \pm 2.1$ \\
\hline & Con A & $885.7 \pm 187.8$ & $632.1 \pm 229.6$ \\
\hline \multirow{3}{*}{ IL-6 } & Saline & $8.5 \pm 0.1$ & $6.9 \pm 0.5^{* *}$ \\
\hline & LPS & $58.6 \pm 6.1$ & $7.9 \pm 1.7^{* * *}$ \\
\hline & Con A & $30.9 \pm 2.7$ & $17.5 \pm 4.6^{*}$ \\
\hline \multirow{3}{*}{ IL-10 } & Saline & $20.8 \pm 0.2$ & $21.8 \pm 1.1$ \\
\hline & LPS & $117.7 \pm 8.6$ & $101.9 \pm 20.1$ \\
\hline & Con A & $59.8 \pm 21.3$ & $65.3 \pm 22.2$ \\
\hline \multirow{3}{*}{ TNF- $\alpha / \mathrm{IL}-10$} & Saline & $5.194 \pm 0.883$ & $1.543 \pm 0.298^{*}$ \\
\hline & LPS & $2.605 \pm 0.206$ & $0.425 \pm 0.105^{* * *}$ \\
\hline & Con A & $3.503 \pm 0.571$ & $1.790 \pm 0.343$ \\
\hline \multirow{3}{*}{ IL-6/IL-10 } & Saline & $0.409 \pm 0.011$ & $0.317 \pm 0.014^{* * *}$ \\
\hline & LPS & $0.522 \pm 0.081$ & $0.078 \pm 0.105^{* *}$ \\
\hline & Con A & $0.778 \pm 0.201$ & $0.308 \pm 0.019$ \\
\hline
\end{tabular}

(a) Values were shown as mean \pm SD. (b) ${ }^{*} p<0.05,{ }^{* *} p<0.01$, and ${ }^{* * *} p<$ 0.001 represents significantly different from the 'control'. (c) The sensitivity limitation of ELISA kits used in this study was $<15.6 \mathrm{pg} / \mathrm{mL}$. (d) The treatment concentrations of lipopolysaccharide (LPS) and concanavalin A (Con A) were $2.5 \mu \mathrm{g} / \mathrm{mL}$.

results also demonstrated that LPS and CD40L synergistically stimulated proliferation of mouse splenocytes in a TLR4-dependent manner [18]. ELISA data showed that FKA has a differential effect on the secretion of pro- (TNF- $\alpha$, IL-1 $\beta$, and IL-2) and anti-inflammatory cytokines (IL-10). Proinflammatory cytokines were downregulated whereas, the anti-inflammatory cytokine was upregulated which is

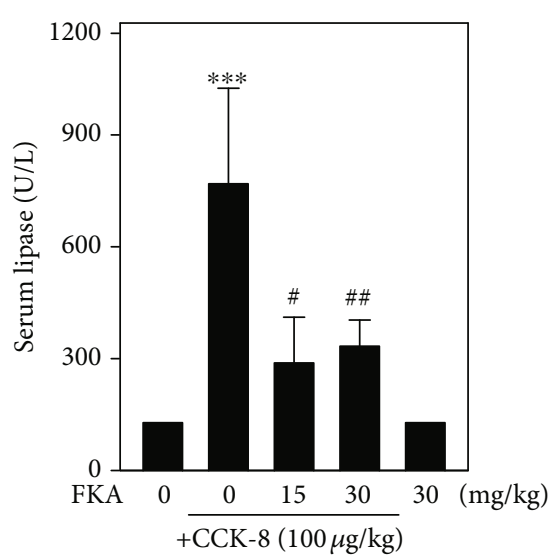

FIgURe 6: FKA suppressed the serum lipase levels in CCK-8induced experimental pancreatitis in $\mathrm{BALB} / \mathrm{c}$ mice. $\mathrm{BALB} / \mathrm{c}$ mice were orally administered with FKA (15 or $30 \mathrm{mg} / \mathrm{kg}$ in $0.1 \%$ DMSO for $2 \mathrm{~h}$ ) followed by intraperitoneal (i.p.) injections of cholecystokinin-8 (CCK-8). 0.5, 1.5, 2.5, and $4 \mathrm{~h}$ after the CCK-8 injections, blood samples were collected from the retroorbital sinus of all mice and serum lipase levels were measured using a commercial serum lipase ELISA kit (R\&D System, Minneapolis, $\mathrm{MN}$, USA). Results were represented as the mean \pm SD of four experiments. Significant at ${ }^{* *} p<0.01$ compared to the control animals; significant at ${ }^{\#} p<0.05$ compared to the CCK8administered animals.

inferring that FKA exerts anti-inflammatory properties. (Figures 1(c)-1(f)).

LPS-stimulated macrophages are the widely used cellular model in the anti-inflammatory studies $[32,33]$. Therefore, in the current study, primary splenocytes were stimulated with LPS to initiate an inflammatory reaction and the effect of FKA was demonstrated. Our data showed that $2.5 \mu \mathrm{g} / \mathrm{mL}$ of LPS-stimulated the dramatic upregulation of TNF- $\alpha$, IL$1 \beta$, IL-2, and IL-10 cytokines. However, FKA pretreatment has significantly downregulated the secretions of TNF- $\alpha$, IL- $1 \beta$, and IL- 2 at all of the concentrations of FKA. Moreover, in the case of IL-10, this suppression was observed at $30 \mu \mathrm{M}$ FKA only. This data provides us the fact that FKA acts as a potent anti-inflammatory agent that protects the splenocytes from the inflammatory insult (Figure 2).

Recent evidence suggests that ROS is involved in inflammatory reactions, and LPS-induced ROS generation was widely studied in various in vitro and in vivo systems $[34,35]$. Of particular importance to this study, ROS are oxidative products released by the mitochondria, peroxisomes, cytochrome p450 metabolism, and inflammatory cell activation from endotoxins in macrophages [36]. Consistent with the literature reports, our flow cytometry study data also showed that LPS alone treatment has dramatically upregulated the ROS levels in primary splenocytes. However, this effect was significantly and dose dependently suppressed due to FKA pretreatment (Figure 3(a)). Consistent with this, western blot data also indicated that the expression of nuclear p65, iNOS, COX-2, TNF- $\alpha$, and IL- $1 \beta$ proteins were significantly upregulated due to the LPS challenge. However, FKA pretreatment has significantly attenuated this effect signifying that FKA blocked the transcriptional activation of 


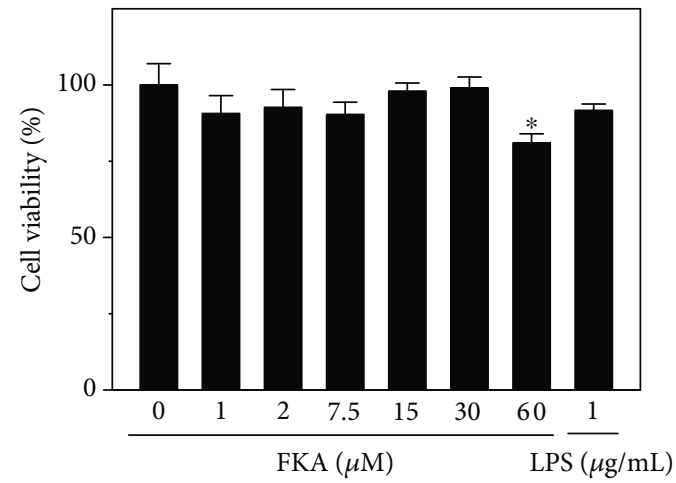

(a)

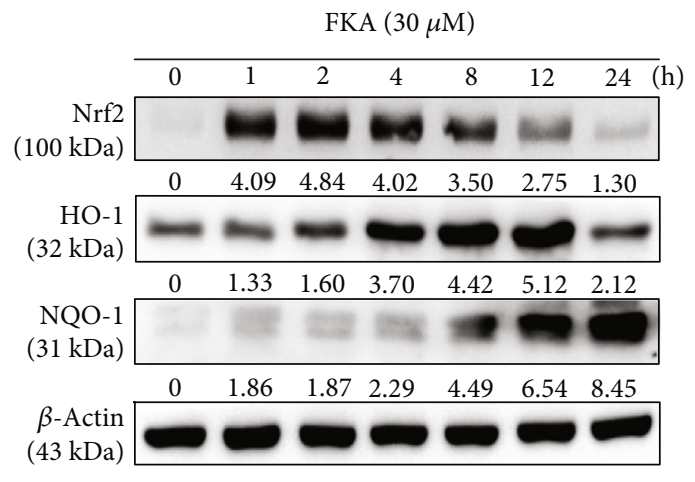

(b)

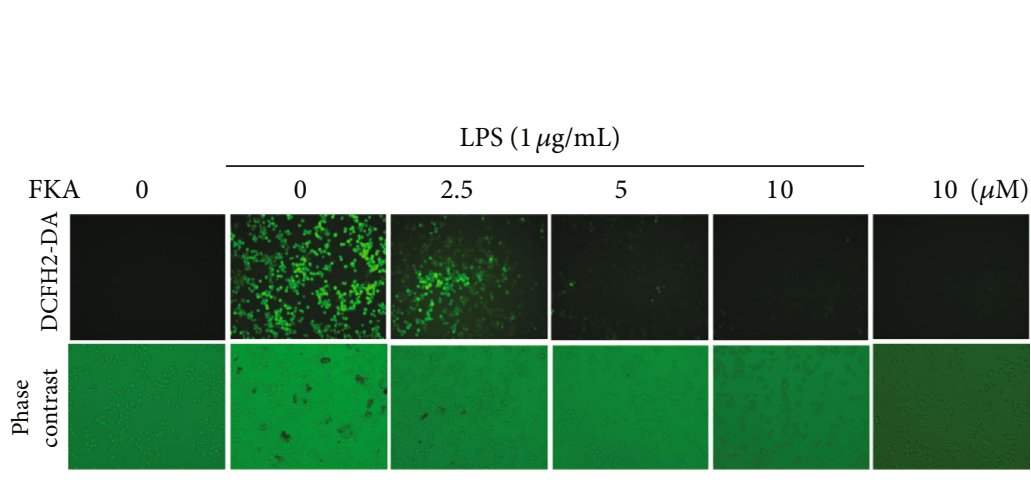

(c)

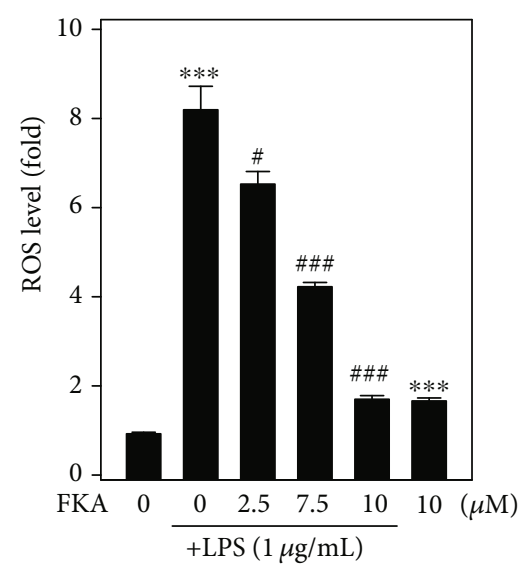

(d)

FIGURE 7: FKA attenuated the LPS-stimulated ROS generation in RAW 264.7 macrophages through the Nrf2 pathway. (a) Effect of FKA concentration on the viability of RAW 264.7 macrophages. Cells were treated with FKA (1-60 $\mu \mathrm{M})$ or LPS (1 $\mathrm{g} / \mathrm{mL})$ for $24 \mathrm{~h}$. Cell viability was determined by MTT assay. (b) FKA induced the expression of Nrf2, HO-1, and NQO-1 proteins in RAW 264.7 macrophages. Cells were pretreated with $30 \mu \mathrm{M}$ FKA for 1-24h. The protein expressions of Nrf2, HO-1, and NQO-1 were determined by the western blot technique. $\beta$-Actin was used as internal controls. (c, d) FKA attenuates ROS generation in LPS-stimulated RAW 264.7 macrophages. Cells were pretreated with FKA $(0,2.5-10 \mu \mathrm{M})$ for $2 \mathrm{~h}$ and then stimulated without or with LPS $(1 \mu \mathrm{g} / \mathrm{mL})$ for $24 \mathrm{~h}$. The intracellular ROS levels were measured by the DCF fluorescence method using fluorescence microscopy (200x magnification). Data were represented as fold change along with the fluorescent image. Results were represented as the mean \pm SD of three experiments. Statistical significance was assigned as ${ }^{*} p<0.05,{ }^{* *} p<0.01$, and ${ }^{* * *} p<0.001$ compared to the control cells and ${ }^{\#} p<0.05$, ${ }^{\# \#} p<0.01$, and $\# \# p<0.001$ compared to the LPS-treated cells.

p65 leading to the downstream suppression of inflammatory enzymes and cytokine protein expression (Figures 3(b)-3(f)).

Previous studies have reported that plant-derived natural products can mediate chemoprevention and cytoprotection through anti-inflammatory and antioxidant mechanisms (Nrf2/ARE) [37]. A well-known antioxidant enzyme, HO-1, has an important role in the defense of LPS-induced ROS generation and inflammation in macrophages [38]. Evidence from the literature has suggested that $\mathrm{HO}-1$ expression is driven by Nrf2 and the products of this activity likely inhibit NO production [39]. The induction of antioxidant genes is the mechanism (HO-1, NQO-1, and $\gamma$-GCLC) that allows Nrf2 to inhibit LPS-induced inflammation [40, 41]. Our western blot data showed that FKA enhanced the nuclear accumulation of $\mathrm{Nrf} 2$, a transcription factor for antioxidant gene expression, inducing the expression of antioxidant genes HO-1, NQO-1, and $\gamma$-GCLC (Figure 4). This was in line with previous reports that indicated many plant extracts do contain anti-inflammatory agents and inhibit ROS formation via the activation of Nrf2 cascades in macrophages [14].

The detailed molecular mechanism on FKA-mediated Nrf2 translocation was not yet fully established. We assume that increased basal ROS levels (low concentrations) by FKA within a short time may attribute to activate the Nrf2 in splenocytes. Though ROS is harmful, low concentrations of ROS are speculated to be involved in redox signaling that may contribute to normal cellular functions and in the prevention of diseases [27]. Erlank et al. reported that in the arterioles and capillaries, in association with the outer surface of the cells and by diffusion, low concentrations of polyphenols generate $\mathrm{H}_{2} \mathrm{O}_{2}$ that activates $\mathrm{Nrf} 2$ signaling and cell adaptation to oxidative stress [42]. In another study, 
Nakazato et al. demonstrated that catechin (a polyphenol from green tea)-mediated ROS was involved in the induction of apoptosis in human malignant cells. It was also explained that polyphenol-induced ROS is capable of modifying the $\mathrm{SH}$-residue in Keap-1 that may lead to Nrf2 activation [43]. When ROS induces the oxidation of specific cysteine residues of Keap-1, Nrf2 can no longer sequester by Keap1 and is subsequently translocated into the cell nucleus, and then binds to the promoter and activates the transcription of antioxidant enzymes [44]. By keeping this in view, in the current study, we tested the effect of FKA on the basal ROS levels in primary splenocytes that are involved in the activation and translocation of Nrf2. Our flow cytometry data showed that splenocytes exposed to FKA exhibited remarkable increase in the basal ROS levels within a short duration of time (5 min) signifying the fact that FKAinduced ROS is critically involved in the activation of the Nrf2/ARE signaling pathway in splenocytes (Figure 5).

Besides primary splenocytes, the anti-inflammatory efficacy of FKA was demonstrated in one of the widely used in vitro experimental cellular models, RAW 264.7, a murine macrophage cell line. The fluorescence microscope data demonstrated that LPS-induced tremendous ROS production ( 8-fold) in RAW 264.7 cells, which was dramatically diminished in the presence of FKA (Figures $7(\mathrm{c})$ and $7(\mathrm{~d})$ ). Also, FKA promoted the upregulation of the expressions of Nrf2, HO-1, and NQO-1 proteins in these cells (Figure 7(b)). Interestingly, similar to primary splenocytes, FKA did not show a significant deleterious effect on the viability of RAW264.7 macrophages signifying that FKA is safe to use as an anti-inflammatory agent (Figure $7(\mathrm{a})$ ).

Pancreatitis is an inflammatory disorder of the pancreas with symptoms ranging from mild to death. Cholecystokinin (CCK) or, its predominant active form, sulfated carboxyterminal octapeptide (CCK-8) were reported to be used as inducers of experimental pancreatitis that increases the secretion of immunoglobulins in vivo and modulates lymphoproliferation $[45,46]$. CCK-8 develops from a large amount of white pulp that acts as a chemoattractant for human monocytes and rat macrophages in the spleen [47]. Elevated plasma CCK concentrations were observed in patients as well as in various animal models of acute pancreatitis [48]. The in vivo anti-inflammatory efficacy of FKA was demonstrated in CCK-8-induced experimental pancreatitis in $\mathrm{BALB} / \mathrm{c}$ mice using serum lipase levels as the marker enzyme. Consistent with the in vitro data obtained from primary splenocyte or RAW 264.7 cell lines, in vivo data also demonstrated that in the presence of CCK- 8 there was a significant upregulation of serum lipase levels inferring the fact that CCK-8-induced strong inflammatory pancreatitis in the mice. However, pretreatment with FKA attenuated the serum lipase levels (Figure 6). Li et al. tested the biochemical serum analysis of various enzymes as well as the histopathological examination of the liver, kidney, colon, lung, heart, spleen, and thymus tissues for the in vivo demonstration of FKA-induced toxicity in mice. In that study, the effect of FKA on the functionality of the pancreas was tested by measuring the activity of serum lipase enzyme as a marker enzyme. Results from their study (biochemical serum analysis and histopathological) has confirmed normal organ function in FKA-treated mice inferring the protective effects of FKA at tissue and biochemical levels [49]. Based on this report, in our study, we speculate that the preadministration of FKA might be reversing the malfunctioning of the pancreas (experimentally induced due to cholecystokinin) at the tissue level leading to the reduction in the serum lipase levels when compared to the mice that did not take FKA.

This was also evidenced by the expression profiles of various pro- and anti-inflammatory cytokines secreted from the control-, LPS- or concanavalin A-stimulated primary splenocytes derived from the FKA-pretreated BALB/c mice. Con A is a plant mitogen used to study the immune regulation of various immune cells because it can stimulate mouse $T$ cell subsets and shows four functionally distinct $\mathrm{T}$ cell populations [50]. Our data demonstrated that due to the FKA pretreatment, control -, LPS- and Con A-stimulated primary splenocytes showed a significant downregulation of TNF- $\alpha$, IL-1 $\beta$, IL-2, and IL-6 proinflammatory cytokines. Interestingly, control, LPS, or Con A has no significant effect on IL-10 secretions (Table 1) suggesting that FKA is a potent anti-inflammatory and antioxidant Kava-kava derivative that has beneficial effects in the development of novel therapeutic compounds to treat diseases associated with the dysregulation of inflammatory cells.

\section{Conclusion}

In summary, the sublethal concentrations of chalcone FKA inhibited ROS, NF $\kappa \mathrm{B}$, iNOS, and COX-2 expressions leading to the suppression of proinflammatory TNF- $\alpha$, IL- $1 \beta$, IL-2, and IL-6 secretions in the LPS-stimulated primary splenocytes. We demonstrated that the anti-inflammatory and antioxidant efficacy of FKA is leading to the induction of antioxidant genes HO-1, NQO-1, and $\gamma$-GCLC via the Nrf2/ARE signaling pathways. The in vivo study results also confirmed that FKA pretreatment has an important role in the downregulation of serum lipase levels in the CCK8-induced experimental pancreatitis in $\mathrm{BALB} / \mathrm{c}$ mice. Therefore, chalcone flavokawain A could be a promising plant-derived immunomodulatory and antioxidant agent that can be used to treat the diseases associated with inflammatory disorders.

\section{Abbreviations}

TNF- $\alpha$ : Tumor necrosis factor- $\alpha$

IL-1 $\beta$ : Interleukin- $1 \beta$

IL-2: $\quad$ Interleukin-2

IL-10: Interleukin-10

LPS: $\quad$ Lipopolysaccharide

iNOS: Inducible nitric oxidase

COX-2: Cyclooxygenase-2

HO-1: Hemoxygenase-1

NQO-1: NADPH dehydrogenase-1

$\gamma$-GCLC: Glutamate-cysteine ligase catalytic subunit

CCK-8: Cholecystokinin-8

Con A: Concanavalin A. 


\section{Data Availability}

The data used to support the findings of this study are included within the article.

\section{Conflicts of Interest}

The authors reported no potential conflict of interest in this article.

\section{Acknowledgments}

This study was supported by the Ministry of Science and Technology (grants MOST-106-2320-B-039-054-MY3 and MOST-107-2320-B-039-013-MY3), Asia University, and China Medical University, Taiwan (CMU 107-ASIA-15). This work was financially supported by the "Chinese Medicine Research Center, China Medical University” from The Featured Areas Research Center Program within the framework of the Higher Education Sprout Project by the Ministry of Education (MOE), Taiwan (CMRC-CHM-8). We are very much thankful to all the funding agencies that supported this research study.

\section{References}

[1] L. Ferrero-Miliani, O. H. Nielsen, P. S. Andersen, and S. E. Girardin, "Chronic inflammation: importance of NOD2 and NALP3 in interleukin-1beta generation," Clinical and Experimental Immunology, vol. 147, no. 2, pp. 227-235, 2007.

[2] S. M. Opal and V. A. DePalo, "Anti-inflammatory cytokines," Chest, vol. 117, no. 4, pp. 1162-1172, 2000.

[3] R. E. Mebius and G. Kraal, "Structure and function of the spleen," Nature Reviews. Immunology, vol. 5, no. 8, pp. 606616, 2005.

[4] M. Guha and N. Mackman, "LPS induction of gene expression in human monocytes," Cellular Signalling, vol. 13, no. 2, pp. 85-94, 2001.

[5] B. Kaminska, "MAPK signalling pathways as molecular targets for anti-inflammatory therapy-from molecular mechanisms to therapeutic benefits," Biochimica et Biophysica Acta, vol. 1754, no. 1-2, pp. 253-262, 2005.

[6] M. Valko, C. J. Rhodes, J. Moncol, M. Izakovic, and M. Mazur, "Free radicals, metals and antioxidants in oxidative stressinduced cancer," Chemico-Biological Interactions, vol. 160, no. 1, pp. 1-40, 2006.

[7] T. Liu, L. Zhang, D. Joo, and S. C. Sun, "NF- $\kappa$ B signaling in inflammation," Signal Transduction and Targeted Therapy, vol. 2, no. 1, 2017.

[8] R. Mulder, A. Banete, and S. Basta, "Spleen-derived macrophages are readily polarized into classically activated (M1) or alternatively activated (M2) states," Immunobiology, vol. 219, no. 10 , pp. 737-745, 2014.

[9] J. W. Jeong, W. S. Lee, S. C. Shin, G. Y. Kim, B. T. Choi, and Y. H. Choi, "Anthocyanins downregulate lipopolysaccharideinduced inflammatory responses in BV2 microglial cells by suppressing the NF- $\kappa \mathrm{B}$ and Akt/MAPKs signaling pathways," International Journal of Molecular Sciences, vol. 14, no. 1, pp. 1502-1515, 2013.

[10] J. K. Kundu and Y. J. Surh, "Breaking the relay in deregulated cellular signal transduction as a rationale for chemoprevention with anti-inflammatory phytochemicals," Mutation Research, vol. 591, no. 1-2, pp. 123-146, 2005.

[11] A. T. Dinkova-Kostova, P. Talalay, J. Sharkey et al., “An exceptionally potent inducer of cytoprotective enzymes: elucidation of the structural features that determine inducer potency and reactivity with Keap1," The Journal of Biological Chemistry, vol. 285, no. 44, pp. 33747-33755, 2010.

[12] M. J. Alcaraz, A. M. Vicente, A. Araico, J. N. Dominguez, M. C. Terencio, and M. L. Ferrandiz, "Role of nuclear factor-kappaB and heme oxygenase- 1 in the mechanism of action of an antiinflammatory chalcone derivative in RAW 264.7 cells," British Journal of Pharmacology, vol. 142, no. 7, pp. 1191-1199, 2004.

[13] K. Itoh and M. Yamamoto, "Transcriptional regulation of the phase II drug detoxifying enzyme genes," Tanpakushitsu Kakusan Koso, vol. 44, 15 Suppl, pp. 2370-2376, 1999.

[14] Y. J. Surh, "Cancer chemoprevention with dietary phytochemicals," Nature Reviews Cancer, vol. 3, no. 10, pp. 768-780, 2003.

[15] H. R. Dharmaratne, N. P. Nanayakkara, and I. A. Khan, "Kavalactones from Piper methysticum, and their 13C NMR spectroscopic analyses," Phytochemistry, vol. 59, no. 4, pp. 429-433, 2002.

[16] D. J. Kwon, S. M. Ju, G. S. Youn, S. Y. Choi, and J. Park, "Suppression of iNOS and COX-2 expression by flavokawain A via blockade of NF- $\kappa$ B and AP-1 activation in RAW 264.7 macrophages," Food and Chemical Toxicology, vol. 58, pp. 479-486, 2013.

[17] H. L. Yang, V. Thiyagarajan, J. W. Liao et al., “Toona sinensis inhibits murine leukemia WEHI-3 cells and promotes immune response in vivo," Integrative Cancer Therapies, vol. 16, no. 3, pp. 308-318, 2017.

[18] K. H. Lin, K. C. Lin, W. J. Lu, P. A. Thomas, T. Jayakumar, and J. R. Sheu, "Astaxanthin, a carotenoid, stimulates immune responses by enhancing IFN-gamma and IL-2 secretion in primary cultured lymphocytes in vitro and ex vivo," International Journal of Molecular Sciences, vol. 17, no. 1, 2016.

[19] X. Liu, S. Yin, Y. Chen et al., "LPS-induced proinflammatory cytokine expression in human airway epithelial cells and macrophages via NF- $\kappa \mathrm{B}$, STAT3 or AP-1 activation," Molecular Medicine Reports, vol. 17, no. 4, pp. 5484-5491, 2018.

[20] Y. C. Hseu, F. Y. Wu, J. J. Wu et al., "Anti-inflammatory potential of Antrodia camphorata through inhibition of iNOS, COX-2 and cytokines via the NF- $\kappa$ B pathway," International Immunopharmacology, vol. 5, no. 13-14, pp. 19141925, 2005.

[21] Y. C. Hseu, M. S. Lee, C. R. Wu et al., "The chalcone flavokawain $\mathrm{B}$ induces $\mathrm{G} 2 / \mathrm{M}$ cell-cycle arrest and apoptosis in human oral carcinoma HSC-3 cells through the intracellular ROS generation and downregulation of the Akt/p38 MAPK signaling pathway," Journal of Agricultural and Food Chemistry, vol. 60, no. 9, pp. 2385-2397, 2012.

[22] C. T. Chang, Y. C. Hseu, V. Thiyagarajan et al., "Chalcone flavokawain $\mathrm{B}$ induces autophagic-cell death via reactive oxygen species-mediated signaling pathways in human gastric carcinoma and suppresses tumor growth in nude mice," Archives of Toxicology, vol. 91, no. 10, pp. 3341-3364, 2017.

[23] Y. V. Gowrisankar and M. A. Clark, “Angiotensin II induces interleukin-6 expression in astrocytes: Role of reactive oxygen species and NF- $\kappa \mathrm{B}$," Molecular and Cellular Endocrinology, vol. 437, pp. 130-141, 2016.

[24] N. Abu, N. E. Mohameda, N. Tangarajoo et al., "In vitro toxicity and in vivo immunomodulatory effects of flavokawain A 
and flavokawain B in Balb/C mice," Natural Product Communications, vol. 10, no. 7, pp. 1199-1202, 2015.

[25] Y. V. Gowrisankar and M. A. Clark, "Regulation of angiotensinogen expression by angiotensin II in spontaneously hypertensive rat primary astrocyte cultures," Brain Research, vol. 1643, pp. 51-58, 2016.

[26] S. M. Ahmed, L. Luo, A. Namani, X. J. Wang, and X. Tang, "Nrf2 signaling pathway: pivotal roles in inflammation," Biochimica et Biophysica Acta - Molecular Basis of Disease, vol. 1863, no. 2, pp. 585-597, 2017.

[27] M. Hultqvist, L. M. Olsson, K. A. Gelderman, and R. Holmdahl, "The protective role of ROS in autoimmune disease," Trends in Immunology, vol. 30, no. 5, pp. 201-208, 2009.

[28] G. J. Seifert, K. C. Sander, S. Richter, and U. A. Wittel, "Murine genotype impacts pancreatitis severity and systemic inflammation: an experimental study," Annals of medicine and surgery, vol. 24, pp. 8-14, 2017.

[29] C. O. Okoli and P. A. Akah, "Mechanisms of the antiinflammatory activity of the leaf extracts of Culcasia scandens P. Beauv (Araceae)," Pharmacology, Biochemistry, and Behavior, vol. 79, no. 3, pp. 473-481, 2004.

[30] A. Murakami and H. Ohigashi, "Targeting NOX, INOS and COX-2 in inflammatory cells: chemoprevention using food phytochemicals," International Journal of Cancer, vol. 121, no. 11, pp. 2357-2363, 2007.

[31] J. Y. Kim, S. J. Park, K. J. Yun, Y. W. Cho, H. J. Park, and K. T. Lee, "Isoliquiritigenin isolated from the roots of Glycyrrhiza uralensis inhibits LPS-induced iNOS and COX-2 expression via the attenuation of NF- $\kappa$ B in RAW 264.7 macrophages," European Journal of Pharmacology, vol. 584, no. 1, pp. 175184, 2008.

[32] B. R. Pinho, C. Sousa, P. Valentao, and P. B. Andrade, "Is nitric oxide decrease observed with naphthoquinones in LPS stimulated RAW 264.7 macrophages a beneficial property?" PLoS One, vol. 6, no. 8, p. e24098, 2011.

[33] T. L. Wadsworth and D. R. Koop, "Effects of the wine polyphenolics quercetin and resveratrol on pro- inflammatory cytokine expression in RAW 264.7 macrophages," Biochemical Pharmacology, vol. 57, no. 8, pp. 941-949, 1999.

[34] S. Cuzzocrea, D. P. Riley, A. P. Caputi, and D. Salvemini, "Antioxidant therapy: a new pharmacological approach in shock, inflammation, and ischemia/reperfusion injury," Pharmacological Reviews, vol. 53, no. 1, pp. 135-159, 2001.

[35] K. Rahman, "Studies on free radicals, antioxidants, and co-factors," Clinical Interventions in Aging, vol. 2, no. 2, pp. 219-236, 2007.

[36] M. Mohsenzadegan and A. Mirshafiey, "The immunopathogenic role of reactive oxygen species in Alzheimer disease," Iranian Journal of Allergy, Asthma, and Immunology, vol. 11, no. 3, pp. 203-216, 2012.

[37] Y. J. Surh and H. K. Na, "NF-kappaB and Nrf2 as prime molecular targets for chemoprevention and cytoprotection with anti-inflammatory and antioxidant phytochemicals," Genes \& Nutrition, vol. 2, no. 4, pp. 313-317, 2008.

[38] J. P. Roach, E. E. Moore, D. A. Partrick et al., "Heme oxygenase-1 induction in macrophages by a hemoglobinbased oxygen carrier reduces endotoxin-stimulated cytokine secretion," Shock, vol. 31, no. 3, pp. 251-257, 2009.

[39] F. A. Wagener, H. D. Volk, D. Willis et al., "Different faces of the heme-heme oxygenase system in inflammation," Pharmacological Reviews, vol. 55, no. 3, pp. 551-571, 2003.
[40] W. Droge, "Free radicals in the physiological control of cell function," Physiological Reviews, vol. 82, no. 1, pp. 47-95, 2002.

[41] R. K. Thimmulappa, K. H. Mai, S. Srisuma, T. W. Kensler, M. Yamamoto, and S. Biswal, "Identification of Nrf2regulated genes induced by the chemopreventive agent sulforaphane by oligonucleotide microarray," Cancer Research, vol. 62, no. 18, pp. 5196-5203, 2002.

[42] H. Erlank, A. Elmann, R. Kohen, and J. Kanner, "Polyphenols activate $\mathrm{Nrf} 2$ in astrocytes via $\mathrm{H} 2 \mathrm{O} 2$, semiquinones, and quinones," Free Radical Biology \& Medicine, vol. 51, no. 12, pp. 2319-2327, 2011.

[43] T. Nakazato, K. Ito, Y. Ikeda, and M. Kizaki, "Green tea component, catechin, induces apoptosis of human malignant $\mathrm{B}$ cells via production of reactive oxygen species," Clinical Cancer Research, vol. 11, no. 16, pp. 6040-6049, 2005.

[44] N. Wakabayashi, A. T. Dinkova-Kostova, W. D. Holtzclaw et al., "Protection against electrophile and oxidant stress by induction of the phase 2 response: fate of cysteines of the Keap1 sensor modified by inducers," Proceedings of the National Academy of Sciences of the United States of America, vol. 101, no. 7, pp. 2040-2045, 2004.

[45] J. Alverdy, E. Stern, S. Poticha, D. Baunoch, and T. Adrian, "Cholecystokinin modulates mucosal immunoglobulin a function," Surgery, vol. 122, no. 2, pp. 386-393, 1997.

[46] J. J. Hyun and H. S. Lee, "Experimental models of pancreatitis," Clinical endoscopy, vol. 47, no. 3, pp. 212-216, 2014.

[47] P. Sacerdote, M. R. Ruff, and C. B. Pert, "Cholecystokinin and the immune system: receptor-mediated chemotaxis of human and rat monocytes," Peptides, vol. 9, Suppl 1, pp. 29-34, 1988.

[48] D. Jia, M. Yamamoto, and M. Otsuki, "Effect of endogenous cholecystokinin on the course of acute pancreatitis in rats," World Journal of Gastroenterology, vol. 21, no. 25, pp. 77427753, 2015.

[49] X. Li, X. Xu, T. Ji et al., "Dietary feeding of Flavokawain a, a kava chalcone, exhibits a satisfactory safety profile and its association with enhancement of phase II enzymes in mice," Toxicology Reports, vol. 1, pp. 2-11, 2014.

[50] J. M. Dwyer and C. Johnson, "The use of concanavalin A to study the immunoregulation of human T cells," Clinical and Experimental Immunology, vol. 46, no. 2, pp. 237-249, 1981. 